\title{
Preservation of Categorical Perception for Speech in Autism With and Without Speech Onset Delay
}

\author{
Liliane Chiodo (), Laurent Mottron, and Steve Majerus
}

\begin{abstract}
Recent accounts of autistic perception, including Bayesian accounts, hypothesize a reduced influence of prior knowledge on perception across different domains in the autism spectrum (AS). The purpose of this study was to investigate the influence of prior linguistic knowledge, in the form of phonemic categorical knowledge, on speech perception in adults with AS condition. As phonemic categorical knowledge is shaped by language experience and abilities, we furthermore distinguished AS participants with (AS-SOD) or without a history of speech onset delay (AS-noSOD); the control group comprises typical individuals matched for age, nonverbal intelligence, and reading abilities. We also controlled for the influence of auditoryverbal short-term retention capacities by administering word list and nonword list repetition tasks. We did not observe any reduced influence of prior phonemic knowledge on the perception of speech stimuli nor did we observed any increased perceptual abilities for atypical variants of speech stimuli or nonspeech auditory stimuli, either between the two autistic groups or relative to the control group. Short-term memory abilities appeared to be superior in the AS-noSOD group relative to the AS-SOD and control groups, but this strength could be accounted for by their higher vocabulary knowledge. The preservation of categorical perception in verbal autistic adults observed in this study challenges models claiming a reduced influence of prior knowledge on perception across domains in the AS. Autism Res 2019, 00: 1-14. (C) 2019 International Society for Autism Research, Wiley Periodicals, Inc.
\end{abstract}

\begin{abstract}
Lay Summary: A reduced influence of prior knowledge has been considered to characterize perceptual abilities in people with autism. In this article, we examine this claim by assessing nonlinguistic and linguistic auditory perception abilities in adults with autism, and by further distinguishing between autism with or without a history of delayed language development. We did not observe any reduced influence of prior language knowledge on the perception of speech stimuli nor did we observe any increased perceptual abilities for atypical variants of speech stimuli or nonspeech auditory stimuli, and this relative to a control group matched on age, nonverbal intellectual efficiency, and reading abilities. Our results challenge models claiming a reduced influence of prior knowledge on perception across domains in the AS.
\end{abstract}

Keywords: autism spectrum; categorical perception; speech onset delay; cognition; Bayesian models

\section{Introduction}

Peaks in perceptual abilities have been considered as being a hallmark feature of cognition in people presenting with autism spectrum (AS) disorder [Mottron et al., 2018]. Perceptual peaks have been proposed to characterize perceptual abilities across domains, such as the visual and auditory processing domains. In the visual modality, examples of perceptual peaks are illustrated by an increased ability to process complex visuospatial information or by an increased reliance on perceptual features in nonverbal reasoning tasks [Gliga et al., 2015; Caron et al., 2006; Soulières et al., 2009]. In the auditory modality, these peaks are illustrated by higher abilities in both children and adults with AS disorder to discriminate and categorize the pitch of simple and complex sinusoidal sounds as compared to non-autistic controls [Heaton, Davis, \& Happé, 2008; Bonnel et al., 2003; Jones et al., 2009]. An increased proportion of autistic individuals also show absolute pitch processing [Lepistö et al., 2009; Teder-Sälejärvi, Pierce, Courchesne, \& Hillyard, 2005]. These peaks have been explained by various accounts, such as the enhanced perceptual model [Mottron, Dawson, Soulières, Hubert, \& Burack, 2006; Meilleur, Jelenic, \& Mottron, 2015] considering enhanced bottom-up processing and nonmandatory use of linguistic knowledge and expectations in perceptual tasks, with tasks processed at the hierarchically lowest possible perceptual level. More recent Bayesian accounts have also been proposed by considering an increased reliance on bottom-up perceptual information due to a reduced intervention of prior knowledge, too precise bottom-up perceptual processing or inflexible updating of prior knowledge [Brock, 2012; Lawson et al.,

From the Psychology and Neuroscience of Cognition Research Unit, Université de Liège, Liège, Belgium (L.C., S.M.); Département de Psychiatrie, Université de Montréal, et Hôpital Rivière-des-Prairies, CIUSSS-NIM, Montréal, Quebec, Canada (L.M.); Fonds de la Recherche Scientifique F.R.S.-FNRS, Brussels, Belgium (S.M.)

Received November 7, 2018; accepted for publication May 7, 2019

Address for correspondence and reprints: Liliane Chiodo, Psychology and Neuroscience of Cognition Research Unit, Université de Liège, Place des Orateurs 1, Bât. B33, Sart Tilman, Quartier Agora, 4000 Liège, Belgium. E-mail: lchiodo@uliege.be

Published online 00 Month 2019 in Wiley Online Library (wileyonlinelibrary.com)

DOI: 10.1002 aur.2134

(c) 2019 International Society for Autism Research, Wiley Periodicals, Inc. 
2014; Pellicano \& Burr, 2012; Van de Cruys et al., 2014]. Overall, the general assumption behind these different accounts is that perception in the AS is characterized by a decreased or dysfunctional intervention of pre-existing knowledge on perception across different domains and hence an increased reliance on bottom-up perceptual features. The aim of this study is to re-examine this assumption by examining categorical perception for speech in autism, by furthermore distinguishing between autism with or without a history of speech delay. Categorical perception of speech provides an interesting opportunity for testing the reduced prior knowledge account of perception in autism as categorical perception is a well-studied paradigm in the field of speech perception and provides a detailed specification of the role prior linguistic knowledge should exert on the perception of speech sounds.

The categorical speech perception paradigm allows us to simultaneously investigate bottom-up and top-down (prior knowledge) processes in speech perception. Native language sounds are generally perceived in a categorical manner based on prior knowledge. A difference between two speech sounds is only perceived if knowledge about the acoustic characteristics of speech sounds allows to categorize the two speech sounds as belonging to two different phonemic categories (e.g., /b/ vs. /p/); intra-categorical acoustic variations (e.g., different acoustic variations close to the prototypical, i.e., the most frequently encountered-acoustic properties of the phoneme $/ \mathrm{b} /$ ) tend not to be perceived in discrimination tasks showing that prior categorical phonemic knowledge exerts a strong top-down effect on the perception of speech stimuli [Kuhl et al., 2008; Liberman, Harris, Hoffman, \& Griffith, 1957]. When presenting pairs of phonemes with variations close to the acoustic properties of a given phoneme (intra-category variations), or with variations involving acoustic features of two different phonemes (between-category variations), discrimination curves for the pairs are characterized by a sharp peak in discrimination performance for phoneme pairs involving between-category acoustic variations, and close to chance-level discrimination for pairs characterized by intra-category acoustic variations. This finding has been considered to reflect the internal phonological categories that have been created in the linguistic system (prior linguistic knowledge) and that facilitate speech perception by top-down, predictive coding of the phonological category best supported by the perceived acoustic input [Kuhl et al., 2008]. If this prior knowledge is reduced or is not used for task performance, then the expected discrimination peak for between-category pairs should disappear, leading to a flatter discrimination curve with similar performance for discrimination of betweencategory and within-category pairs.

With respect to perceptual specificities considered to characterize people with AS conditions, implying a decreased influence of prior knowledge and/or increased precision of bottom-up perceptual processing, we could make the following predictions. If prior knowledge is atypical or less used, then knowledge about the acoustic properties of phoneme categories should less influence performance in categorical speech perception tasks and the discrimination peak observed for between-category stimulus pairs ("b"' vs. "d") should be reduced or absent. If bottom-up perceptual processing is increased, then we should expect better discrimination for within-category pairs (two acoustic variants of the phoneme " $b$ ") in AS people, as compared to control participants.

The literature regarding processing of speech stimuli in AS children and adults provides conflicting findings. On the one hand, at a more general level of linguistic perceptual processing, a comprehensive review of the literature showed increased sensitivity to acoustic contrasts of foreign languages that are generally not perceived by non-native speakers and reduced specialization for the processing of native language sounds in AS children and adolescents [Happé \& Frith, 2006; DePape, Hall, Tillmann, \& Trainor, 2012]. Neuroimaging studies also indicate atypical processing of auditory stimuli, especially for speech sounds, with more widespread activity foci in the brainstem, cerebellum, and parietal regions in individuals with AS, compared to control participants who show activity peaks restricted to the left temporal cortex [Boddaert et al., 2004; Flagg, Cardy, Roberts, \& Roberts, 2005; Kujala, Lepistö, \& Näätänen, 2013; Redcay \& Courchesne, 2008; Zilbovicius et al., 2000; Gervais et al., 2004; Samson, Mottron, Jemel, Belin, \& Ciocca, 2006; O'Connor, 2012; for a review, see Tryfon et al., 2018]. On the other hand, the few studies that focused more specifically on categorical speech perception showed normal range discrimination performance for between-category and within-category stimuli in AS children and adults [You, Serniclaes, Rider, \& Chabane, 2017; Constantino et al., 2007; White et al., 2006; Stewart, Petrou \& Ota, 2018]; only the study by You et al. indicated that prior categorical knowledge about phonemes may be less precise when using an identification task, as characterized by a slightly shallower slope of the identification curve (in these tasks, the participant has to decide whether a given sound is a " $\mathrm{b}$ " or a " $\mathrm{p}$ " rather than judging the similarity of two stimuli).

Besides from the fact that very few studies have assessed categorical speech perception in AS people in a systematic manner, a further problem is that these studies did not distinguish between autism with or without speech onset delay. In the subgroup previously known as Asperger syndrome, speech and later syntax show a normal developmental trajectory, with sometimes even above norm performance [Nader et al., 2015]. Conversely, in the most frequent form of autism, there is a speech onset delay, with favorable development in around $75 \%$ of cases and the other 25\% remaining nonverbal at an adult age despite frequent normal range nonverbal intelligence levels [Wodka et al., 2013; Courchesne et al. 2018]. The present study will 
focus on the two first groups, that is, autistic people presenting functional language use when adults but with or without a delayed onset of language development. Both of these groups can present with verbal working memory impairment in comparison to their fluid intelligence levels even if the impairment is likely to be more severe in the group with speech onset delay [Dawson et al., 2007; Nader et al., 2015]. This distinction between autism with and without speech onset delay is an essential variable when investigating categorical speech perception in the AS, as perceptual and language deficits are known to influence each other. Low-level perceptual abnormalities (such as difficulties in extracting target information from the sound signal while ignoring background noise) may slow down the identification of native language sounds and their characteristics [Flagg, Cardy, Roberts, \& Robert, 2005; Teder-Sälejärvi et al., 2005; Serniclaes et al., 2001]. At the same time, perceptual difficulties can also arise as a consequence of poor language development: illiterate adults show less precise knowledge about phonemic categories [McBride-Chang, 1996; Morais, Bertelson, Cary, \& Alegria, 1986; Serniclaes, 2006]. Importantly, previous studies have demonstrated that only autistic participants with speech onset delay may present atypical auditory perceptual abilities [Bonnel \& Hafter 2006; Bonnel et al., 2010].

The aim of the present study was to use the categorical speech perception paradigm in order to study in a systematic manner bottom-up perceptual processing and the influence of prior knowledge on perception of speech stimuli. Furthermore, we distinguished autism with and without speech delay. In a first task, we assessed categorical perception abilities for a /d/-/t/ continuum. Participants were presented with two between-category or withincategory exemplars of the continuum and they had to decide whether the two sounds are identical or not. If prior knowledge is reduced or used less efficiently, then we should expect a diminished discrimination peak for between-category stimulus pairs; if bottom-up perceptual processing is enhanced or more precise, then we should expect generally increased discrimination performance irrespectively of between-category or within-category stimulus pairs. Of critical interest here was whether these specificities are more prominent in the autism with speech onset delay group, as compared to the autism without speech onset delay group. This rationale was pushed further in a second paradigm that directly contrasted three different perceptual conditions for a continuum of auditory information: a nonspeech condition, a speech condition, and a modulated speech condition. In the nonspeech condition, the sine-waves resulted from a pure sine-wave synthesis method, using an amplitude-weighted sum of sinusoids [Serniclaes et al., 2001; Majerus, 2011]. These sounds are typically perceived as whistles when not explicitly presented as being potential language sounds. Little to no categorical perception is expected for this nonspeech condition even in control participants. In the speech condition, the stimuli were the same, but they were presented as language sounds, favoring categorical perception of the stimuli, along the "b"-"d" continuum. Thus, categorical perception is expected for this speech condition. In the modulated speech condition, the sounds were created following the same procedure as for the other conditions and presented as speech, but with additional low-frequency amplitude modulation. Modulation was reproduced at the F0 frequency (constant at $100 \mathrm{~Hz}$ ), giving the sounds the equivalent of voice pitch and making them sound more like natural speech stimuli. Maximal categorical perception is expected for this continuum. The continua have been validated in previous studies and have shown atypical categorical perception in different neurodevelopmental conditions such as dyslexia and the genetic syndrome microdeletion 7q11.2 (Williams syndrome) [Serniclaes et al., 2001; Majerus, 2011]. If autistic people present reduced prior phonemic knowledge or use less this knowledge in speech perception tasks, then we should again observe reduced discrimination peaks for between-category stimulus pairs and this particularly in the speech and modulated speech conditions where the influence of prior categorical knowledge is expected to be at its maximum in the control population. If autistic subjects have enhanced, bottom-up perceptual abilities, then higher levels of discrimination abilities should be observed for all types of material, and this most markedly for the nonspeech conditions and the between-category sound pairs. Again, of critical interest here was whether this specific pattern of perceptual performance was observed for only the autistic group with speech onset delay or for both groups.

A word list and nonword list repetition task were also presented in order to control for the influence of reduced verbal short-term retention abilities on discrimination performance in the categorical speech perception tasks which require two auditory stimuli to be maintained for a short duration, the time it takes to compare them and to make a decision about their similarity. Reduced verbal working memory abilities have been shown to characterize autistic people with speech onset delay, but have also been observed, even if less consistently, in autistic people without speech onset delay [Samson, Mottron, Jemel, Belin, \& Ciocca, 2006; Williams et al., 2013].

At the level of participant characteristics, we recruited adult autistics, with or without speech onset delay. Recruiting adult, literate individuals ensures that general language skills are sufficiently developed in both groups at the moment of testing, and allows for reliable assessment of categorical speech perception abilities. Furthermore, this recruitment strategy also enabled us to match the autistic groups and the control group at the level of reading age; this is a critical step given the known influence of reading ability and experience on the effect of prior categorical knowledge on speech perception. 
Table 1. Characteristics of the AS-NoSOD, AS-SOD, and Control Groups

\begin{tabular}{|c|c|c|c|c|c|c|}
\hline & $\begin{array}{l}\text { AS-NoSOD } \\
\quad N=17\end{array}$ & $\begin{array}{l}\text { AS-SOD } \\
N=16\end{array}$ & $\begin{array}{l}\text { Controls } \\
N=30\end{array}$ & $\begin{array}{c}\text { AS-NoSOD/AS-SOD } \\
P \text { values }\end{array}$ & $\begin{array}{c}\text { AS-NoSOD/controls } \\
P \text { values }\end{array}$ & $\begin{array}{c}\text { AS-SOD/controls } \\
P \text { values }\end{array}$ \\
\hline Age in years $(S D)$ & $30.23(7.97)$ & $26.56(6.56)$ & $26.9(5.88)$ & 0.16 & 0.10 & 0.85 \\
\hline $\begin{array}{l}\text { Raven's progressive } \\
\text { matrices (SD) (raw scores) }\end{array}$ & $51.58(7.79)$ & $50.12(7.68)$ & $50.23(7.22)$ & 0.59 & 0.55 & 0.96 \\
\hline Reading level in months $(S D)$ & $196.17(43.40)$ & $193.31(68.40)$ & $179.96(50.49)$ & 0.88 & 0.27 & 0.45 \\
\hline FSIQ $(S D)^{\mathrm{a}}$ & 119.69 (15.09) & $93.76(19.80)$ & $111.4(18.36)$ & $0.001 *$ & 0.20 & $0.02 *$ \\
\hline VIQ $(S D)^{\mathrm{a}}$ & $129.53(11.63)$ & $92.75(14.25)$ & $113.8(17.15)$ & $<0.001 *$ & $0.009 *$ & $0.006 *$ \\
\hline PIQ $(S D)^{\mathrm{a}}$ & $110.61(17.15)$ & $104.30(25.22)$ & $109.73(18.26)$ & 0.46 & 0.89 & 0.51 \\
\hline EVIP $(S D)$ (standardized score) & $127.35(4.15)$ & $114.62(10.91)$ & $120.56(8.06)$ & $<0.001 *$ & $0.002 *$ & $0.04 *$ \\
\hline \multicolumn{7}{|l|}{ ADI-R score } \\
\hline Social (SD) & $20.82(5.41)$ & $21.37(3.79)$ & $0.83(0.91)$ & 0.73 & $<0.001^{*}$ & $<0.001^{*}$ \\
\hline Communic. $\quad(S D)$ & $20.11(7.02)$ & $23.75(6.29)$ & $0.6(0.77)$ & 0.12 & $<0.001^{*}$ & $<0.001 *$ \\
\hline Interests $(S D)$ & $7.35(2.14)$ & $8.81(3.12)$ & $1.86(1.79)$ & 0.12 & $<0.001 *$ & $<0.001 *$ \\
\hline $\begin{array}{l}\text { Age at first 2-word } \\
\text { production }(S D) \text { (years) }\end{array}$ & $1.82(0.39)$ & $4.03(1.2)$ & $1.9(0.4)$ & $<0.001 *$ & 0.53 & $<0.001 *$ \\
\hline \multicolumn{7}{|l|}{$\begin{array}{l}\text { Level of education } \\
\text { (number of participants/level) }\end{array}$} \\
\hline Higher level & 14 & 4 & 13 & $<0.001^{*}$ & $0.009 *$ & 0.21 \\
\hline Secondary level & 3 & 11 & 17 & $0.002 *$ & $0.009 *$ & 0.42 \\
\hline Special school & 0 & 1 & 0 & 0.29 & 0 & 0.16 \\
\hline
\end{tabular}

$* P<0.05$ for pairwise $t$-tests corrected for multiple comparisons; for level of education and gender ratio, the $P$ values reflect $\chi^{2}$ tests.

Abbreviations: EVIP, échelle de vocabulaire en image Peabody (French version of the Peabody Picture Vocabulary Test); SD, standard deviation.

${ }^{\mathrm{a}}$ Full-scale IQ (FSIQ), verbal IQ (VIQ), and performance IQ (PIQ) (WAIS-4) were obtained for 13 AS-NoSOD participants, 13 AS-SOD participants, and 15 non-autistic control participants.

\section{Methods \\ Participants}

Thirty-three adults (21 males (M), 12 females (F)) between 18 and 41 years of age, diagnosed as autistic (3/33) or Asperger (30/33) according to DSM-IV criteria by private psychiatrists or autism resource centers in Belgium, France, and Switzerland, were included in this study. All participants were native French speakers. For 16 of the participants, a semi-structured interview using the Autism Diagnostic Interview-revised (ADI-R) [Lord, Rutter, \& Le Couteur, 1994] and the Autism Diagnostic Observation Scale [Lord et al., 1989] had already been conducted by the psychiatrist and/or the autism resource center. For the remaining 17 participants, we validated the autism diagnosis by administering the ADI-R to the parents $(N=18)$ or caregiver $(N=1)$ of autistic participants. Autistic participants were allocated to two subgroups on the basis of showing (AS-SOD; $N=16,13$ males; age range: 18-40 years) or not (AS-NoSOD; $N=17,8$ males; age range: $18-41$ years) a history of speech onset delay, as documented by the ADI questions number 9 (one-word sentences after 24 month) and 10 (two-word sentences after 33 months); 11 individuals of the AS-SOD group presented a delay in two-word sentences, three in one-word sentences, and two a speech delay that could not be further documented. Seven additional participants had been recruited, but their data are not included in the analyses reported here due to chance-level performance for all stimulus pairs on at least one of the two categorical perception tasks (speech conditions only for the second categorical speech perception task). This was done in order to rule out the possibility that the null effects observed for the group variable (see Results) were driven by the inclusion of these participants. ASD groups were matched to a control group for age, reading level [Lefavrais, 1965], and nonverbal intellectual efficiency [Raven's standard progressive matrices; Raven, 1998]. The control group comprises 30 adults $(17 \mathrm{M}, 13 \mathrm{~F})$ aged between 18 and 41 years of age and without a history of psychiatric or neurological conditions (Table 1). These control participants were recruited via announcements of the study to personal and professional networks of the first author. The non-autistic status of the control group was verified by the administration of the ADI-R. Two additional participants had been recruited but their data could not be included due to chance-level performance on the experimental tasks. The statistical values reported in Table 1 confirm that the three groups did not differ at the level of age, nonverbal intelligence (Raven's matrices), reading level, and performance IQ (Wechsler Adult Intelligence Scale-IV [Wechsler, 2011]). As expected [Samson, Zeffiro, Doyon, Benali, \& Mottron, 2015; Dawson, Soulières, Gernsbacher, \& Mottron, 2007], there were significant between-group differences for verbal IQ and full scale IQ, receptive vocabulary (Échelle de vocabulaire en images Peabody-EVIP) [Dunn, ThériaultWhalen, \& Dunn, 1993], and level of education.

This study was approved by the ethics committee of the Faculty of Psychology and Educational Sciences of the University of Liège (Belgium) on 23 April 2014. All participants agreed to participate in this study after reading and signing a written informed consent form. 
Tasks

Categorical perception: d-t continuum-Material. All sounds of this continuum were sine-wave analogues with pitch modulation, making them immediately appear as speech sounds [Majerus, 2011; Medina, Hoonhorst, Bogliotti, \& Serniclaes, 2010]. There were eight stimuli (A, B, C, D, E, F, G, and $\mathrm{H}$ ) ranging from /doe/ (A) to /toe/ (H). Voice-onset time varied from -70 to $+70 \mathrm{msec}$, with incremental steps of $20 \mathrm{msec}$. The stable frequencies of the first, second, and third formants were 493, 1,485, and $2500 \mathrm{~Hz}$, respectively. Onset frequencies of first, second, and third formant transitions were 300, 2,000, and $3100 \mathrm{~Hz}$, respectively (the sound stimuli can be accessed at https://osf.io/t47xw/?view_only=7bb4e8bb99114caa89 e8e9b800ffbe54). The total duration of the sounds varied between 210 (A) and $280 \mathrm{msec}(\mathrm{H})$. Procedure: A first continuum assessed categorical perception abilities for speech stimuli by contrasting stimuli from the /d/-/t/ continuum, with stimuli varying at the level of voice onset time in seven steps, and a theoretical categorical boundary at the mid-point voice onset time values (variant four of the seven stimuli). The stimuli were presented in pairs from adjacent positions of the continuum (e.g., A-B) and participants had to decide whether the two syllables were the same or not. In this type of discrimination task, participants generally identify a difference only for the pairs involving the mid-point stimulus (e.g., CD, DE). A second continuum used the same logic for consonant pairs varying at the level of formant transition values $(/ \mathrm{b} /-/ \mathrm{d} /)$. This continuum included five variants ranging from $/ \mathrm{b} /$ to /d/. Adjacent stimulus pairs $\mathrm{AB}, \mathrm{BC}, \mathrm{CD}, \mathrm{DE}, \mathrm{EF}, \mathrm{FG}$, and $\mathrm{GH}$ and corresponding identical pairs $\mathrm{AA}, \mathrm{BB}, \mathrm{CC}$, $\mathrm{DD}, \mathrm{EE}, \mathrm{FF}, \mathrm{GG}$, and $\mathrm{HH}$ were presented for discrimination. For each condition, each different pair was presented four times in both directions ( $\mathrm{AB}$ or $\mathrm{BA}$ ) with an equivalent number of presentations for identical pairs resulting in 88 trials. The stimulus pairs were selected in random order within each continuum, and presented via high-quality headphones at the rate of 1 stimulus every $2,500 \mathrm{msec}$ via E-Prime 2.0 software running on a PC compatible mobile computer. Stimuli were output at a comfortable listening level. The task instructions were: "You will hear two syllables. The syllables are "deu" or "teu." If you hear twice the same syllable, "deu-deu" or "teu-teu," you press the green button. If the syllables are different, such as "deu"-"teu" or "teu"-"deu," you press the red button. Are you ready?" The participants responded by pushing a button marked with a green sticker for "same" responses, and a button marked with a red sticker for "different" responses. The participants had to respond within 6,000 msec. The task started with eight practice trials. For each condition and for each stimulus pair, we computed $d^{\prime}$ scores to take into account response bias [Macmillan \& Creelman, 1991].
Categorical perception: b-d continuum-Material. This continuum assessed perception and discrimination for both linguistic and nonlinguistic stimuli. The continuum contained six acoustic variations (A, B, C, D, E, and F), varying from $/ \mathrm{ba} /$ to $/ \mathrm{da} /$, and were taken from Serniclaes et al. [2001] and Majerus [2011]. The variants differed exclusively at the level formant transitions, by modulating the initial frequency transition of the second and third sine-waves of each sound, corresponding to the second (F2) and third (F3) formant transitions in natural speech. The onset frequency of the second sine-wave varied between $700 \mathrm{~Hz}$ (/ba/ endpoint)/ and 2,075 Hz (/da/ endpoint), in five equal steps of $275 \mathrm{~Hz}$. The onset frequency of the third sine-wave varied from 1,500 to $3,875 \mathrm{~Hz}$ in five equal steps of $475 \mathrm{~Hz}$. The end frequencies of the second and third sine-wave transitions were set at 1,300 and $2,500 \mathrm{~Hz}$, respectively. The initial frequency of the first sine-wave (F1) was set to $100 \mathrm{~Hz}$, and its end frequency was $750 \mathrm{~Hz}$ (the sound stimuli can be accessed at https://osf.io/t47xw/?view_only=7bb4e8bb99 114 caa89e8e9b800ffbe54). The total duration of each sound was $230 \mathrm{msec}$. As noted before, the stimuli were presented under three conditions: a nonspeech/whistling condition, a speech condition, and a modulated speech condition. In the nonspeech condition, the sine-waves resulted from a pure sine-wave synthesis method using an amplitude-weighted sum of sinusoids [Serniclaes, SprengerCharolles, Carré, \& Démonet, 2001]. In the speech condition, the stimuli were the same, but they were presented as language sounds, favoring categorical perception of the stimuli. In the modulated speech condition, the sounds were created following the same procedure as for the other conditions, but with additional low-frequency amplitude modulation at the F0 frequency (constant at $100 \mathrm{~Hz}$ ), giving the sounds the equivalent of voice pitch and making sound more like natural speech stimuli. The nonspeech condition was presented first in order to favor a nonlinguistic acoustic processing strategy, followed by the speech and the modulated speech conditions. Procedure: Adjacent stimulus pairs $\mathrm{AB}, \mathrm{BC}, \mathrm{CD}, \mathrm{DE}$, and $\mathrm{EF}$ and corresponding identical pairs $\mathrm{AA}, \mathrm{BB}, \mathrm{CC}, \mathrm{DD}, \mathrm{EE}$, and $\mathrm{FF}$ were presented for discrimination. For each condition, the number of presentation of stimulus pairs followed the same procedure as for the previous task, resulting in 64 trials per condition. For the nonspeech continuum, the task instructions were the following: "You will hear two sounds. When the two sounds are identical, you push the green button; when they are different, you push the red button. Are you ready? Here we go." For the speech continuum, the task instructions were adapted in order to present the same sounds as potential speech sounds: "This time, you will hear two-word sounds, "ba" and "da." If you hear twice the same word, "ba-ba" or "da-da," you press the green button. If the words are different, such as "ba"-"da" or "da"-"ba," you press the red button. Are you ready?" For 
the modulated speech continuum, the instructions were the following: "You will now hear the same words pronounced by a different voice. As before, if you hear twice the same words, "ba-ba" or "da-da," you press the green button. If the words are different, you press the red button. Are you ready?" As for the first task, $d$ ' scores were computed, and this separately for each presentation condition (nonspeech, speech, and modulated speech). The participants had to respond within $6,000 \mathrm{msec}$. The task started with four practice trials.

\section{Immediate serial recall task of word and nonword}

lists-Material. A list of 84 consonant-vowel-consonant (CVC) words and a second list of $84 \mathrm{CVC}$ nonwords were created. The phonotactic frequency of $\mathrm{CV}$ and $\mathrm{VC}$ biphones of nonwords was matched to those of words on the basis of a French phonetic database [Tubach \& Boe, 1990; Majerus, 2011, 2013]. The stimuli were presented in lists ranging from 2 to 6 items, with four lists per length. Procedure: The word and nonword stimuli were regrouped in sequences of increasing length for immediate serial recall; the shortest sequence contained two stimuli and the longest sequence contained six stimuli. There were four trials for each stimulus type at each list length. For each sequence length, the four trials for the word and nonword stimuli were presented before proceeding to the next sequence length. The participants were asked to repeat each sequence immediately after its auditory presentation by the examiner, the items of each list being presented at the rate of 1 item/sec. Responses were recorded on tape and transcribed for later scoring. The total number of correctly recalled items (item score) and in correct serial position (serial order score) was determined separately for the word and nonword list conditions, by pooling over the different sequence lengths. The task instructions were as follows: "I will present you $2(3,4,5,6)$ words. You will repeat these words in the same order. If for a certain position, you know that there is a word, but you do not know which one, you say 'Forgotten' for that word."

\section{Order of the Tasks}

The tasks were administered in two sessions, with the first session including the anamnestic interviews and Raven's matrices. In the second session, the two categorical speech perception tasks were administered, with the b-d continuum first, followed by the word and nonword list repetition tasks, and finally the tasks measuring receptive vocabulary knowledge and reading age, the latter tasks being the least subject to fatigue effects. For the categorical speech perception task: b-d continuum, the nonspeech condition was presented first, followed by the speech and then the modulated speech conditions in order to avoid any speech-based acoustic decisions based on prior knowledge.

\section{Statistical Analyses}

Besides standard, frequentist mixed analysis of variances (ANOVAs), we conducted Bayesian ANOVAs to allow for a direct test of the null hypothesis. Bayesian methods allow us to estimate the evidence both against and for the null hypothesis to be quantified, whereas classical inference methods can only provide evidence against, but not for, the null hypothesis [Dienes, 2014]. Bayesian analyses were conducted using the JASP statistical package [Wagenmakers et al., 2018], using default values for prior distribution parameters. We used the decision criterions proposed by Lee \& Wagenmakers [2014], considering a Bayes factor (BF) $<3$ as anecdotal evidence, between 3 and 10 as moderate evidence, between 10 and 30 as strong evidence, between 30 and 100 as very strong evidence, and >100 as decisive evidence for a given model relative to another model or the null model. $\mathrm{BF}_{10}$ values reflect evidence in favor of the effect of interest, and $\mathrm{BF}_{01}$ reflect evidence for the null effect.

\section{Results \\ Categorical Speech Perception Task: d-t Continuum}

For the d-t continuum a mixed ANOVA on $d^{\prime}$ scores was conducted as a function of group (AS-NoSOD, AS-SOD, and controls) and stimulus pairs (AB, BC, CD, DE, EF, FG, and $\mathrm{GH})$. We observed a main effect of stimulus pairs, $F(3.7,224.34)=178.87, \mathrm{MSE}=0.46, P<0.001, \eta_{\mathrm{p}}^{2}=0.75$. The main effect of group was not significant, $F(2,60)=1.14, \mathrm{MSE}=0.35, P=0.33, \eta_{\mathrm{p}}^{2}=0.04$; the same was also true for the group by stimulus pair interaction, $F(7.5,224.3)=0.72, \mathrm{MSE}=0.46, P=0.66, \eta_{\mathrm{p}}^{2}=0.02$. Planned comparisons indicated that the stimulus pair corresponding to the theoretical perceptual boundary (pair DE) was more often judged to be different than other pairs (see Table 2 and Fig. 1). These results are supported by a Bayesian ANOVA showing strong evidence for the inclusion of the stimulus pair effect $\left(\mathrm{BF}_{\text {inclusion }}+\infty\right)$. BF inclusion for group effect was close to zero (0.06). A direct test of the null hypothesis for the group effect yielded strong evidence for the absence of a group effect, with $\mathrm{BF}_{01}=21.13$. Similar results were observed when assessing response times. A mixed ANOVA on response times revealed no effect of stimulus pair, $F(4.51,271.1)=0.97$, MSE $=391,158, P=0.43, \eta_{\mathrm{p}}^{2}=0.02$, no effect of group, $F(2,60)=0.28, \mathrm{MSE}=728,501 P=0.76, \eta_{\mathrm{p}}^{2}=0.009$, and no pair-by-group interaction, $F(9.0,271.1)=1.43$, MSE $=391,158, P=0.18, \eta_{p}^{2}=0.04$. Bayesian mixed ANOVA confirmed the absence of a group effect, with $\mathrm{BF}_{01}=3.04$ (see Fig. 2). To sum up, the results for this first categorical perception task do not show any evidence for a diminished influence of prior phonemic knowledge on speech perception (no reduced discrimination peak for the stimulus pair of the phonemic category boundary relying 
Table 2. Planned comparisons for discrimination performance of pairs corresponding to the theoretical categorical boundary and other pairs for " $d-t^{\prime}$ " and the " $b-d$ " continua (with Bonferroni corrections for multiple comparisons)

\begin{tabular}{lrccc}
\hline & $F$ & $d f$ & $p_{\text {Bonferroni }}$ & $\eta^{2}{ }^{2}$ \\
\hline$d$ - $t$ continuum & & & & \\
DE vs. AB & 233.40 & 1,62 & $<0.01$ & 0.79 \\
DE vs. BC & 505.90 & 1,62 & $<0.01$ & 0.89 \\
DE vs. CD & 449.40 & 1,62 & $<0.01$ & 0.88 \\
DE vs. EF & 644.60 & 1,62 & $<0.01$ & 0.91 \\
DE vs. FG & 658.30 & 1,62 & $<0.01$ & 0.91 \\
DE vs. GH & 723.20 & 1,62 & $<0.01$ & 0.92 \\
$b$ - $d$ continuum & & & & \\
Nonspeech & & & & \\
CD vs. AB & 28.43 & 1,62 & $<0.005$ & 0.31 \\
CD vs. BC & 3.67 & 1,62 & 0.24 & 0.06 \\
CD vs. DE & 28.97 & 1,62 & $<0.005$ & 0.32 \\
CD vs. EF & 26.00 & 1,62 & $<0.005$ & 0.30 \\
Speech & & & & \\
CD vs. AB & 40.94 & 1,62 & $<0.005$ & 0.40 \\
CD vs. BC & 3.76 & 1,62 & 0.23 & 0.06 \\
CD vs. DE & 16.46 & 1,62 & $<0.005$ & 0.21 \\
CD vs. EF & 39.91 & 1,62 & $<0.005$ & 0.39 \\
Modulated speech & & & & \\
CD vs. AB & 119.60 & 1,62 & $<0.005$ & 0.66 \\
CD vs. BC & 55.20 & 1,62 & $<0.005$ & 0.47 \\
CD vs. DE & 107.70 & 1,62 & $<0.005$ & 0.64 \\
CD vs. EF & 112.80 & 1,62 & $<0.005$ & 0.65 \\
\hline
\end{tabular}

most on prior knowledge) or for enhanced bottom-up perceptual abilities (no enhanced discrimination for withincategory stimulus pairs). These results were independent of the language history of the participants, AS-SOD and ASnoSOD groups showing the same pattern of results. In statistics, the mean squared error (MSE) or mean squared deviation (MSD) of an estimator (of a procedure for estimating an unobserved quantity) measures the average of the squares of the errors-that is, the average squared difference between the estimated values and what is estimated.

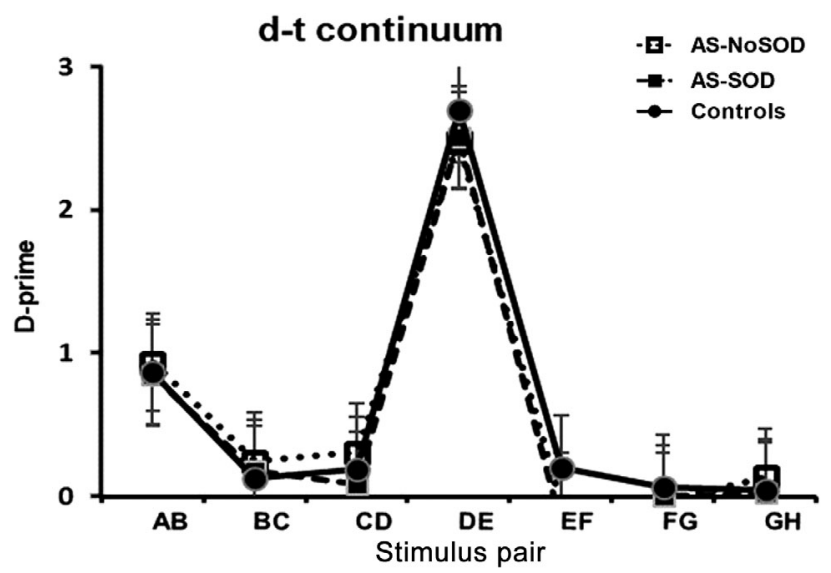

Figure 1. Discrimination performance for the d-t continuum as a function of stimulus pair and group. Bars indicate standard errors.

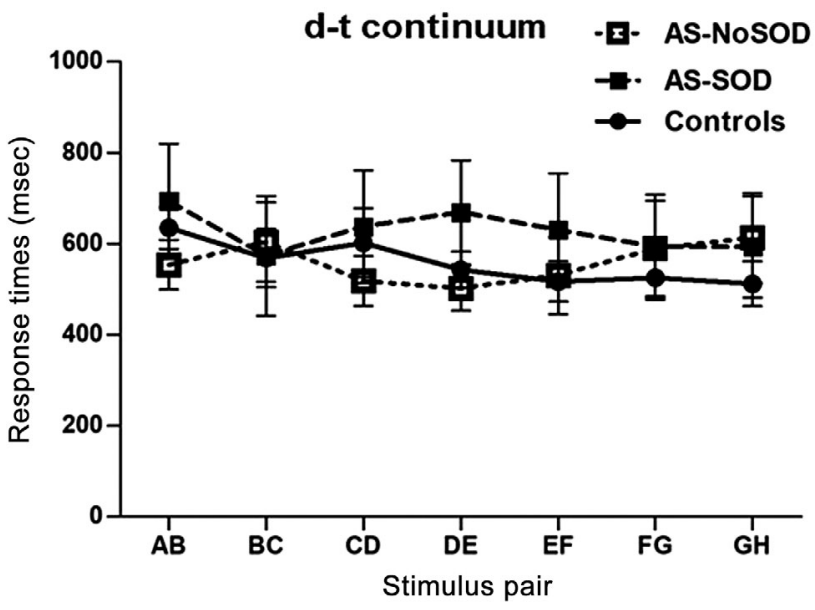

Figure 2. Response times for the d-t continuum as a function of stimulus pair and group. Bars indicate standard errors.

\section{Categorical Speech Perception Task: B-d Continuum}

For the b-d continuum, a mixed ANOVA was conducted on $d^{\prime}$ scores, with the group factor (AS-NoSOD, AS-SOD, and controls) as a between-subject variable, and stimulus pairs $(\mathrm{AB}, \mathrm{BC}, \mathrm{CD}, \mathrm{DE}$, and $\mathrm{EF})$ as well as conditions (nonspeech, speech, and modulated speech) as within-subject variables. We observed a main effect of stimulus pairs, $F(2.1,125.8)=44.99, \mathrm{MSE}=1.78, P<0.001, \eta_{\mathrm{p}}^{2}=0.43$ and a main effect of conditions, $F(1.8,108.4)=6.23$, MSE $=0.47, P=003, \eta_{\mathrm{p}}^{2}=0.09$, further characterized by a condition-by-stimulus pair interaction, $F(5.35,321.2)=8.67$, MSE $=0.48, P<0.001, \eta_{\mathrm{p}}^{2}=0.13$. The highest $d^{\prime}$ scores were observed for the stimulus pair corresponding to the perceptual boundary (pair CD) relative to all other pairs. Planned comparisons indicated that this effect was most pronounced in the modulated speech condition (see Table 2). No other effects were significant at $P<0.05$ : group effect, $F(2,60)=0.78, \mathrm{MSE}=1.56, P=0.47, \eta_{\mathrm{p}}^{2}=0.02$, condition-by-group interaction, $F(3.61,108.4)=0.48$, MSE $=0.47, P=0.74, \eta_{\mathrm{p}}^{2}=0.01$, pair-by-group interaction, $F(4.19,125.8)=0.29, \mathrm{MSE}=1.78, P=0.89, \eta_{\mathrm{p}}^{2}=0.009$, and condition-by-pair-by-group interaction, $F(10.7,321.2)=$ 0.66 , MSE $=0.48, P=0.77, \eta_{\mathrm{p}}^{2}=0.02$. In sum, the three groups showed the expected categorical perception behavior and its interaction with the speech vs. nonspeech conditions (see Fig. 3). The absence of a group effect was further confirmed by running the same analysis using a Bayesian mixed ANOVA. An analysis of specific effects showed very strong evidence for the inclusion of the condition $\left(\mathrm{BF}_{\text {inclusion }}=995572.72\right)$ and stimulus pair $\left(\mathrm{BF}_{\text {inclusion }}\right.$ $=3.22 \mathrm{e}+15)$ effects as well as for the condition-by-stimulus pair $\left(\mathrm{BF}_{\text {inclusion }}=733428.43\right)$ interaction. $\mathrm{BF}_{\text {inclusion }}$ for the group effect was close to zero (0.028). A direct test of the null hypothesis for the group effect yielded strong evidence for the absence of a group effect, with $\mathrm{BF}_{01}=16.91$. 

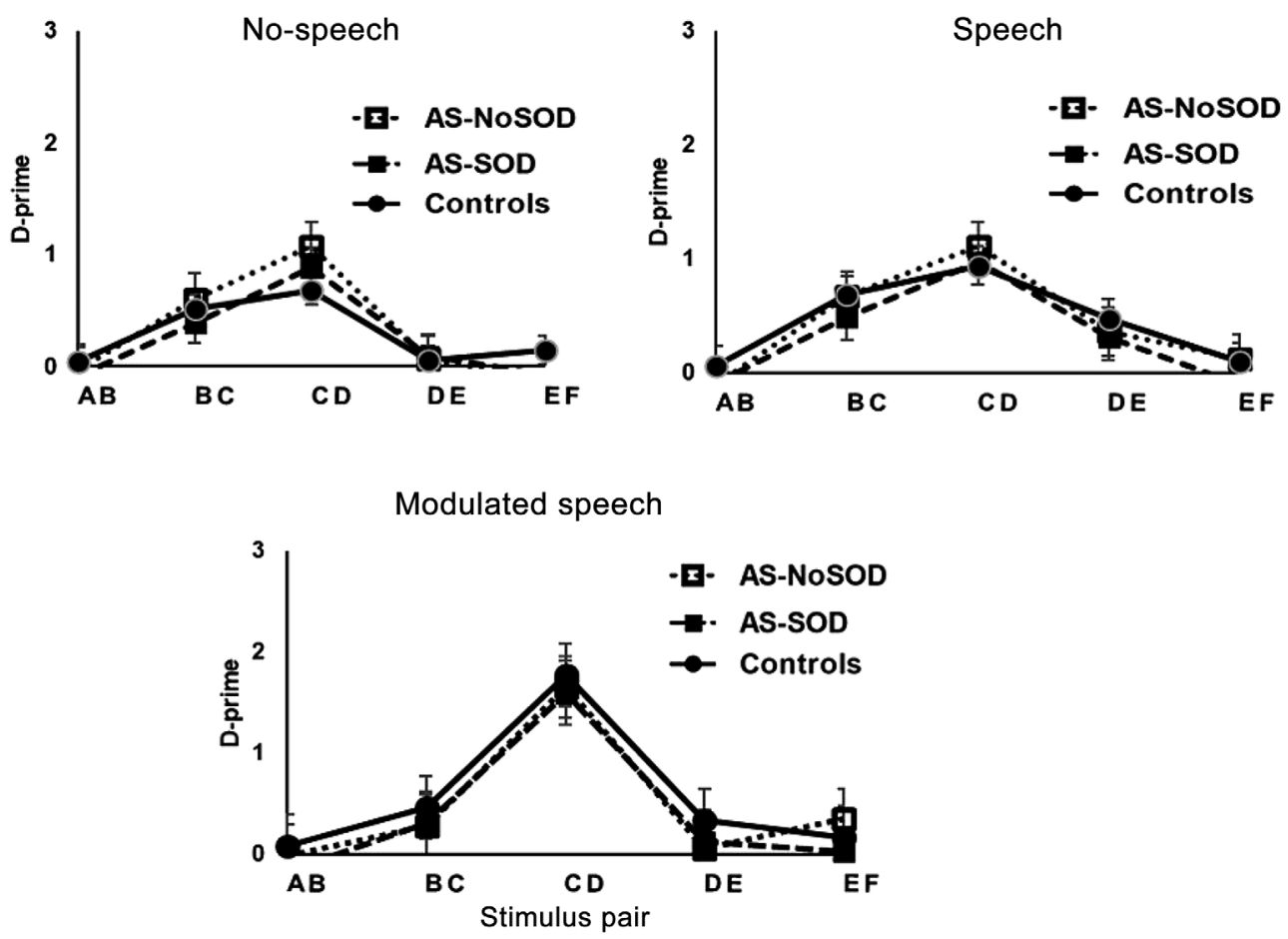

Figure 3. Discrimination performance for the b-d continuum as a function of stimulus pair, task condition, and group. Bars indicate standard errors.

We also conducted the same set of analyses on response times. A mixed ANOVA indicated a main effect of condition, with particularly slowed responses for the nonspeech condition, $F(1.5,89.11)=27.52, \mathrm{MSE}=283983$, $P<0.001, \eta_{\mathrm{p}}^{2}=0.32$. No other effects were significant at $P<0.05$ : group effect, $F(2,59)=0.55, \mathrm{MSE}=1961552$, $P=0.58, \eta_{\mathrm{p}}^{2}=0.02$, condition-by-group interaction, $F$ $(3.0,89.1)=0.53, \mathrm{MSE}=283983, P=0.71, \eta_{\mathrm{p}}^{2}=0.02$, pairby-group interaction, $F(6.5,191.8)=0.48$, MSE $=68200$, $P=0.84, \eta_{\mathrm{p}}^{2}=0.02$, and condition-by-pair-by-group interaction, $F(11.4,335.7)=0.76$, MSE $=70461, P=0.68$, $\eta_{\mathrm{p}}^{2}=0.02$. The absence of a group effect was again tested by a Bayesian mixed ANOVA. An analysis of Bayesian specific effects showed very strong evidence for the inclusion of the condition effect $\left(\mathrm{BF}_{\text {inclusion }}=3.22 \mathrm{e}+15\right) . \mathrm{BF}_{\text {inclusion }}$ for group effect was close to zero (0.102). A direct test of the null hypothesis for the group effect yielded moderate evidence for the absence of a group effect, with $\mathrm{BF}_{01}=4.13$ (see Fig. 4).

To sum up, the results for this second categorical perception task replicated those of the first task, by showing no evidence for a diminished influence of prior phonemic knowledge on speech perception (no reduced discrimination peak for the stimulus pair of the phonemic category boundary relying most on prior knowledge) or for enhanced bottom-up perceptual abilities (no enhanced discrimination for within-category stimulus pairs, no enhanced performance for the nonspeech condition). These results were independent of the language history of the participants, AS-SOD, and AS-noSOD groups showing the same pattern of results.

\section{Immediate Serial Recall Tasks}

Finally, we assessed performance on the word and nonword immediate serial recall tasks, as a function of group. A mixed ANOVA with the between-subjects factor "group" and the within-subjects factor "lexicality" on the number of items recalled in correct serial position, we observed a robust effect of group, $F(2,60)=9.10$, $P<0.001, \eta^{2}{ }_{\mathrm{p}}=0.23$ as well as an effect of lexicality, $F$ $(1,60)=232.82, P<0.001, \eta^{2}{ }_{p}=0.79$. The interaction was not significant, $F(2,60)=1.96, P=0.15, \eta_{p}^{2}=0.01$. As shown in Figure 5, word lists led to significantly higher recall performance than nonword lists in all three groups. Independent pairwise $t$-tests indicated that the AS-NoSOD group significantly outperformed the AS-SOD group in the word $\left(p_{\text {Bonferroni }}<0.01\right)$ and nonword $\left(p_{\text {Bonferroni }}<0.05\right)$ conditions as well as the control group in the nonword $\left(p_{\text {Bonferroni }}<0.05\right)$ condition; the control group and the AS-SOD group did not significantly differ for any condition (after Bonferroni corrections for multiple comparisons). The results were confirmed by a Bayesian mixed ANOVA analysis, showing strong evidence for the inclusion of the lexicality effect $\left(\mathrm{BF}_{\text {inclusion }}+\infty\right)$ and the group effect $\left(\mathrm{BF}_{\text {inclusion }}=62.13\right)$. $\mathrm{BF}_{\text {inclusion }}$ for the interaction was associated with anecdotal evidence $\left(\mathrm{BF}_{\text {inclusion }}=2.26\right)$. Next, we checked the 

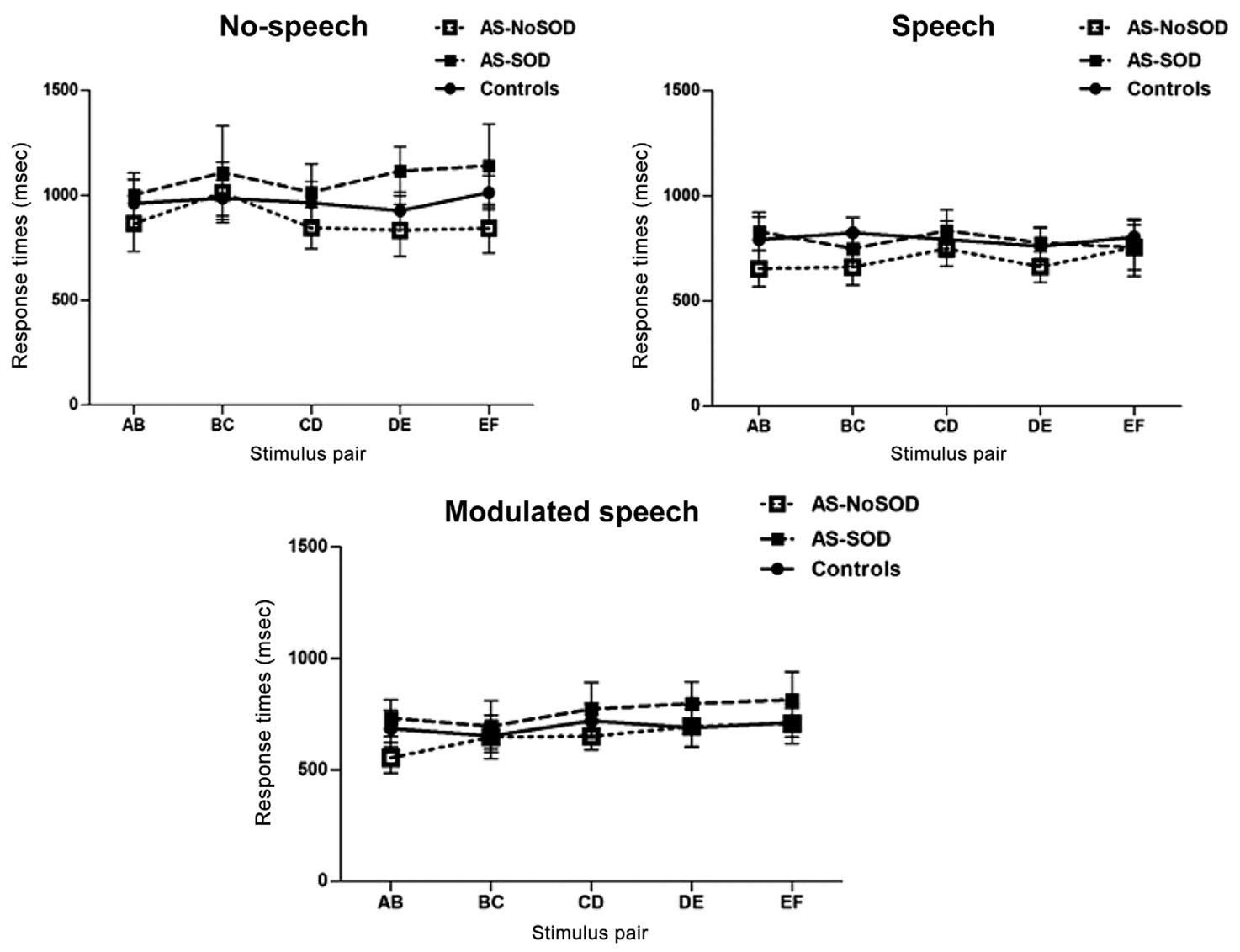

Figure 4. Response times for the b-d continuum as a function of stimulus pair, task condition, and group. Bars indicate standard errors.

extent to which these differences are associated with the superior language abilities in the AS-noSOD group, by conducting a series of ANCOVA analyses with the receptive vocabulary scores (EVIP) as a covariate. The group effect became nonsignificant when adding EVIP as a covariate for both the word $(F(2,59)=2.12$, $\left.P=0.13, \eta_{\mathrm{p}}^{2}=0.05\right)$ and the nonword $(F(2,59)=2.88$, $\left.P=0.06, \eta_{\mathrm{p}}^{2}=0.08\right)$ conditions. This was also

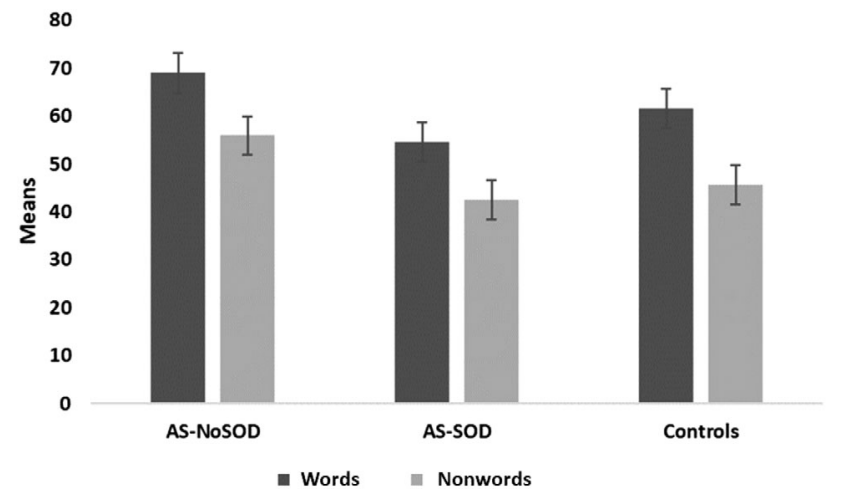

Figure 5. Serial recall performance in the immediate serial recall task as a function of stimulus condition and group. Bars indicate standard errors. confirmed by a Bayesian ANCOVA analysis, with anecdotal evidence for a group effect for word $\left(\mathrm{BF}_{\text {inclusion }}=0.776\right)$ and nonword $\left(\mathrm{BF}_{\text {inclusion }}=1.60\right)$ conditions after introducing the EVIP as a covariate. In sum, the results show that the AS-NoSOD group presents superior performance for verbal immediate serial recall relative to both AS-SOD and control groups, but this superiority is the reflection of the superior verbal

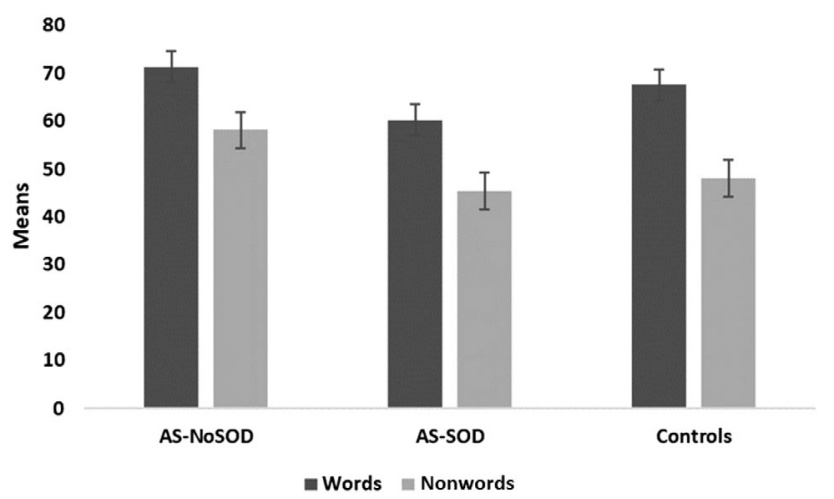

Figure 6. Recall performance in the immediate serial recall task as a function of stimulus condition and group. Bars indicate standard errors. 
abilities in the AS-noSOD group, as estimated by the EVIP receptive vocabulary measure. This finding is not surprising given that the AS-noSOD group included participants that had presented normal language development leading to higher adult language abilities as compared to the AS-SOD group. Given the absence of group differences in the categorical speech perception tasks, this finding of superior verbal working memory and language abilities is unlikely to have biased the results of the speech perception tasks (Fig. 6).

\section{Discussion}

The purpose of this study was to investigate the hypothesis of an altered influence of prior knowledge and of increased bottom-up processing in auditory-verbal perceptual tasks in adult verbal autistic people. We furthermore distinguished autism with and without speech onset delay by assuming that perceptual specificities may be most marked in autistic participants with speech onset delay. We did not observe any reduced influence of prior knowledge on a categorical speech perception task, both groups showing discrimination peaks of similar size as the control group for between-category stimulus pairs, which are most influenced by phoneme category knowledge. Furthermore, we did not observe any increased bottom-up perceptual processing, both groups showing the same level of discrimination as controls for within-category stimulus pairs and for stimuli in a nonspeech condition.

The results of the present study provide robust evidence for normal range processing in categorical speech perception tasks in adult, verbal participants with autism. Although some previous studies already showed typical discrimination performance in categorical speech perception tasks in both children and adults with autism [White et al., 2006; Constantino et al., 2007; Stewart et al., 2018], the present results show that these results are not due to the specific language histories of autistic participants as identical results were observed for autistic groups with and without speech onset delay. Furthermore, our results show that these results are not specific to speech-level processing as typical discrimination performance was observed for the auditory stimuli used in this study, whether task instructions emphasized or de-emphasized speech-level processing of the stimuli. Critically, our study also controlled for reading abilities and we were able to match the autistic and control groups on reading performance. A previous study that showed some subtle evidence for a reduced influence of prior knowledge on speech perception did not control for reading ability and hence the potentially poorer reading abilities of the autistic children in that study may have led to the less precise phoneme identification behavior that was observed [You et al., 2017]. Reading ability is an important factor to control when studying categorical speech perception since reading experience will increase the precision of categorical phonemic representations [McBride-Chang, 1996; Morais, Bertelson, Cary, \& Alegria, 1986; Serniclaes, 2006].

The present results allow to constrain the different theoretical accounts that have been proposed to explain the specific perceptual behaviors observed in the AS. At the level of Bayesian accounts, several theories have been proposed. A first theory considers that prior knowledge is reduced or less precise, resulting in a weaker impact of prior knowledge on performance in perceptual tasks [Pellicano \& Burr, 2012]. In perceptual categorization tasks, this would imply that knowledge about phonological categories should be reduced, leading to smaller discrimination peaks at phonemic category boundaries. The present results are not in favor of this account, at least as regards the perception of speech stimuli, as the autistic participants showed a similar phonemic category boundary suggesting a normal influence of phonological knowledge associated with the different phoneme categories that were tested here. A second theory considers that bottom-up perceptual information is encoded with increased or aberrant precision [Brock, 2012; Lawson, Rees, \& Friston, 2014]. In the present case, this would translate in overall higher discrimination performance particularly for within-category stimulus pairs and for stimulus pairs when presented as nonspeech stimuli. Our results, showing no increased discrimination performance for within-category phonemic variants or for stimuli when presented as nonspeech stimuli, do not support this second account either. We should note here that in other domains, including the visual domain for which the first Bayesian accounts were proposed, evidence in favor of these two accounts is highly contradictory [e.g., Pell et al., 2016; Van der Hallen, Lemmens, Steyaert, Noens, \& Wagemans, 2017]. A third account considers that prior knowledge once acquired will normally influence performance in perceptual task, but if the structure of perceptual information changes, people with autism have difficulties in accurately updating prior knowledge with the new perceptual regularities [Van de Cruys et al., 2014]. This account cannot be tested by the present study as this would require an experiment involving the learning of new phonological categorical information, this information being close or more distant from the participants' existing phonemic categories. Future studies should investigate the ability of people with autism to learn new phonemic categories in the same way as experiments with visual information have done [e.g., SapeyTriomphe, Sonié, Hénaff, Mattout, \& Schmitz, 2018].

A final, non-Bayesian account, the enhanced perceptual model [Mottron et al., 2006], considers that perception in autism is characterized both by enhanced bottom-up perceptual processing and by a nonmandatory use of prior knowledge. This account implies that people with autism 
can use prior knowledge in perceptual tasks but only when it facilitates task performance. This account is partially supported by the present results as categorical phonemic knowledge is essential for efficient speech perception given the extreme natural acoustic variation of phonemic realizations caused by prosodic, emotional, and dialectal characteristics of the speaker or by environmental noise. Hence, when processing speech stimuli, the optimal processing strategy will be a top-down, categorical processing strategy; exact, bottom-up processing of the extremely variable speech signal would lead to perceptual overloading and inefficient identification of speech. However, the assumption of increased bottom-up perceptual processing of the enhanced perceptual model is not supported by the results of the present study, at least as regards the perception of speech stimuli.

One possible conclusion here is that perceptual peaks in autism could characterize the processing of visual information rather than auditory information, or occur in the auditory domain only for simple acoustic stimuli [e.g., Lepistö et al., 2009; Teder-Sälejärvi et al., 2005]. It could, however, also be the case that these perceptual peaks, when observed, are partly an artifact that stems from the type of tasks used to match autistic and control groups: These tasks often rely on verbal intelligence estimates, which can lead to an underestimation of intellectual efficiency in other domains [Dawson, Soulières, Gernsbacher, \& Mottron, 2007; Soulières, Dawson, Gernsbacher, \& Mottron, 2011]. The importance of the use of proper matching variables is shown in the present study by the AS-SOD vs. AS-noSOD distinction: Verbal abilities were specifically reduced or superior while nonverbal intellectual abilities were the same in our two autistic groups. More generally, other studies have shown that some visual perceptual peaks [but not all; see Barbeau, Soulières, Dawson, Zeffiro, \& Mottron, 2013] disappear when autistic and control groups are matched on nonverbal intelligence measures, such as Raven's matrices [Dawson, Soulières, Gernsbacher, \& Mottron, 2007].

We would also like to acknowledge some limitations of this study. The present study only investigated perception in the auditory-verbal domain for a task requiring explicit categorization responses, and we do not know whether our participants would have presented perceptual peaks in tasks focusing on the immediate stages of speech perception (such as online monitoring of brain activity during stimulus presentation) rather than on post-stimulus comparison and judgment processes. Furthermore, we tested a restricted set of linguistic stimuli by examining only two consonant continua. We should, however, note here that the consonant continua that were tested are those that elicit the strongest categorical responses in non-autistic adults and hence were optimally suited for testing the influence of prior phonemic categorical knowledge on speech perception [Kuhl et al., 2008]. Also, studies using other types of continua observed similar results as those reported here [White et al., 2006; Constantino et al., 2007; Stewart et al., 2018; You et al., 2017]. A final limitation of the study is that ADI-R scores for slightly more than half of participants were obtained on an a posteriori basis and the precision of responses to the ADI-R could be somewhat diminished due to memory effects. At the same time, we should note that for all participants, the autistic status had in addition been confirmed by a formal diagnosis from a medical expert specialized in autism disorders.

\section{Conclusions}

The results of this study indicate that autistic adults, with or without speech delay, and with average nonverbal intellectual efficiency and reading abilities, do not exhibit atypical perception of speech and complex nonspeech stimuli in a categorization task. The influence of prior phonemic knowledge and the bottom-up processing of perceptual information are in the normal range, contrasting with hypo-prior and increased perceptual precision Bayesian accounts of autistic perception. Future studies need to determine whether these results are specific to the perception of complex auditory-verbal information as opposed to visual information. The ability to flexibly update prior phonemic knowledge when exposed to novel phonemic information also needs to be explored.

\section{Acknowledgments}

We thank the participants for the time they devoted to this study.

\section{Conflict of Interest}

The authors declare that they have no competing interests.

\section{Availability of Data and Materials}

The datasets used and/or analyzed during the current study are available from the corresponding author upon reasonable request.

\section{Author Contributions}

L.M. provided the research question. S.M. and L.C. designed the study and conducted the analyses. L.C., S.M., and L.M. wrote the manuscript. L.C. collected the data. L.C. transcribed and scored the data. All authors read and approved the final manuscript. 


\section{References}

Barbeau, E. B., Soulières, I., Dawson, M., Zeffiro, T. A., \& Mottron, L. (2013). The level and nature of autistic intelligence III: Inspection time. Journal of Abnormal Psychology, 122(1), 295-301. https://doi.org/10.1037/a0029984

Boddaert, N., Chabane, N., Belin, P., Bourgeois, M., Royer, V., Barthelemy, C., ... Zilbovicius, M. (2004). Perception of complex sounds in autism: Abnormal auditory cortical processing in children. American Journal of Psychiatry, 161(11), 2117-2120. https://doi.org/10.1176/appi.ajp.161.11.2117

Bonnel, A., McAdams, S., Smith, B., Berthiaume, C., Bertone, A., Ciocca, V., ... Mottron, L. (2010). Enhanced pure-tone pitch discrimination among persons with autismbut not Asperger syndrome. Neuropsychologia, 48(9), 2465-2475. https://doi. org/10.1016/j.neuropsychologia.2010.04.020

Bonnel, A., \& Hafter, E. (2006). Sensitivity to increments analyzed separately for each level in a roving paradigm. The Journal of the Acoustical Society of America, 120(5), 3127-3127. https://doi.org/10.1121/1.4787689

Bonnel, A., Mottron, L., Peretz, I., Trudel, M., Gallun, E., \& Bonnel, A.-M. (2003). Enhanced pitch sensitivity in individuals with autism: A signal detection analysis. Journal of Cognitive Neuroscience, 15(2), 226-235. https://doi.org/10.1162/ 089892903321208169

Brock, J. (2012). Alternative Bayesian accounts of autistic perception: Comment on Pellicano and Burr. Trends in Cognitive Sciences, 16(12), 573-574. https://doi.org/10.1016/j.tics.2012.10.005

Caron, M.-J. (2006). Cognitive mechanisms, specificity and neural underpinnings of visuospatial peaks in autism. Brain, 129 (7), 1789-1802. https://doi.org/10.1093/brain/awl072

Constantino, J. N., Yang, D., Gray, T. L., Gross, M. M., Abbacchi, A. M., Smith, S. C., ... Kuhl, P. K. (2007). Clarifying the associations between language and social development in autism: A study of non-native phoneme recognition. Journal of Autism and Developmental Disorders, 37(7), 1256-1263. https://doi.org/10.1007/s10803-006-0269-9

Courchesne, V., Girard, D., Jacques, C., \& Soulières, I. (2018). Assessing intelligence at autism diagnosis: Mission impossible? Testability and cognitive profile of autistic preschoolers. Journal of Autism and Developmental Disorders., 49, 845-856. https://doi.org/10.1007/s10803-018-3786-4

Dawson, M., Soulières, I., Gernsbacher, M., \& Mottron, L. (2007). The level and nature of autistic intelligence. Psychological Science, 18(8), 657-662. https://doi.org/10.1111/j.1467-9280. 2007.01954.x

DePape, A.-M. R., Hall, G. B. C., Tillmann, B., \& Trainor, L. J. (2012). Auditory processing in high-functioning adolescents with autism spectrum disorder. PLoS One, 7(9), e44084. https://doi.org/10.1371/journal.pone.0044084

Dienes, Z. (2014). Using Bayes to get the most out of nonsignificant results. Frontiers in Psychology, 5, 781. https:// doi.org/10.3389/fpsyg.2014.00781

Dunn, L. M., Thériault-Whalen, C. M., \& Dunn, C. M. (1993). Echelle de vocabulaire en images peabody (EVIP). Adaptation française du Peabody Picture Vocabulary test-revised. Manuel pour les formes A et B. Toronto: Psycan.

Flagg, E. J., Cardy, J. E. O., Roberts, W., \& Roberts, T. P. L. (2005). Language lateralization development in children with autism: Insights from the late field magnetoencephalogram.
Neuroscience Letters, 386(2), 82-87. https://doi.org/10.1016/ j.neulet.2005.05.037

Gervais, H., Belin, P., Boddaert, N., Leboyer, M., Coez, A., Sfaello, I., ... Zilbovicius, M. (2004). Abnormal cortical voice processing in autism. Nature Neuroscience, 7(8), 801-802. https://doi.org/10.1038/nn1291

Gliga, T., Bedford, R., Charman, T., Johnson, M. H., BaronCohen, S., Bolton, P., ... Tucker, L. (2015). Enhanced visual search in infancy predicts emerging autism symptoms. Current Biology, 25(13), 1727-1730. https://doi.org/10.1016/j. cub.2015.05.011

Happé, F., \& Frith, U. (2006). The weak coherence account: Detail-focused cognitive style in autism spectrum disorders. Journal of Autism and Developmental Disorders, 36(1), 5-25. https://doi.org/10.1007/s10803-005-0039-0

Heaton, P., Davis, R. E., \& Happé, F. G. E. (2008). Research note: Exceptional absolute pitch perception for spoken words in an able adult with autism. Neuropsychologia, 46(7), 20952098. https://doi.org/10.1016/j.neuropsychologia.2008. 02.006

Jones, C. R. G., Happé, F., Baird, G., Simonoff, E., Marsden, A. J. S., Tregay, J., ... Charman, T. (2009). Auditory discrimination and auditory sensory behaviours in autism spectrum disorders. Neuropsychologia, 47(13), 2850-2858. https://doi.org/ 10.1016/j.neuropsychologia.2009.06.015

Kuhl, P. K., Conboy, B. T., Coffey-Corina, S., Padden, D., RiveraGaxiola, M., \& Nelson, T. (2008). Phonetic learning as a pathway to language: New data and native language magnet theory expanded (NLM-e). Philosophical Transactions of the Royal Society B: Biological Sciences, 363(1493), 979-1000. https://doi.org/10.1098/rstb.2007.2154

Kujala, T., Lepistö, T., \& Näätänen, R. (2013). The neural basis of aberrant speech and audition in autism spectrum disorders. Neuroscience \& Biobehavioral Reviews, 37(4), 697-704. https://doi.org/10.1016/j.neubiorev.2013.01.006

Lawson, R. P., Rees, G., \& Friston, K. J. (2014). An aberrant precision account of autism. Frontiers in Human Neuroscience, 8, 302. https://doi.org/10.3389/fnhum.2014.00302

Lee, M. D., \& Wagenmakers, E.-J. (2014). Bayesian cognitive modeling: A practical course. Cambridge: Cambridge University Press.

Lefavrais, P. (1965). Description, définition et mesure de la dyslexie. Utilisation du test "L'Alouette". Paris: Revue de Psychologie Appliquée.

Lepistö, T., Kuitunen, A., Sussman, E., Saalasti, S., JanssonVerkasalo, E., Nieminen-von Wendt, T., \& Kujala, T. (2009). Auditory stream segregation in children with Asperger syndrome. Biological Psychology, 82(3), 301-307. https://doi. org/10.1016/j.biopsycho.2009.09.004

Liberman, A. M., Harris, K. S., Hoffman, H. S., \& Griffith, B. C. (1957). The discrimination of speech sounds within and across phoneme boundaries. Journal of Experimental Psychology, 54(5), 358-368. https://doi.org/10.1037/h0044417

Lord, C., Rutter, M., Goode, S., Heemsbergen, J., Jordan, H., Mawhood, L., \& Schopler, E. (1989). Autism diagnostic observation schedule: A standardized observation of communicative and social behavior. Journal of Autism and Developmental Disorders, 19(2), 185-212.

Lord, C., Rutter, M., \& Le Couteur, A. (1994). Autism Diagnostic Interview-Revised: A revised version of a diagnostic interview for caregivers of individuals with possible pervasive 
developmental disorders. Journal of Autism and Developmental Disorders, 24(5), 659-685. https://doi.org/10.1007/ BF02172145

Macmillan, N. A., \& Creelman, C. D. (1991). Detection theory: A user's guide. New York: Cambridge University Press.

Majerus, S. (2013). Language repetition and short-term memory: An integrative framework. Frontiers in Human Neuroscience, 7, 357. https://doi.org/10.3389/fnhum.2013.00357

Majerus, S. (2011). L'évaluation de la mémoire à court terme. In X. Seron \& M. Van der Linden (Eds.), Traité de Neuropsychologie Clinique (2ème ed.) Marseille: Solal.

McBride-Chang, C. (1996). Models of speech perception and phonological processing in reading. Child Development, 67 (4), 1836-1856. https://doi.org/10.2307/1131735

Medina, V., Hoonhorst, I., Bogliotti, C., \& Serniclaes, W. (2010). Development of voicing perception in French: Comparing adults, adolescents, and children. Journal of Phonetics, 38(4), 493-503. https://doi.org/10.1016/j.wocn.2010.06.002

Meilleur, A.-A. S., Jelenic, P., \& Mottron, L. (2015). Prevalence of clinically and empirically defined talents and strengths in autism. Journal of Autism and Developmental Disorders, 45 (5), 1354-1367. https://doi.org/10.1007/s10803-014-2296-2

Morais, J., Bertelson, P., Cary, L., \& Alegria, J. (1986). Literacy training and speech segmentation. Cognition, 24(1-2), 45-64. https://doi.org/10.1016/0010-0277(86)90004-1

Mottron, L., Dawson, M., Soulières, I., Hubert, B., \& Burack, J. (2006). Enhanced perceptual functioning in autism: An update, and eight principles of autistic perception. Journal of Autism and Developmental Disorders, 36(1), 27-43. https:// doi.org/10.1007/s10803-005-0040-7

Mottron, L., Soulières, I., \& Dawson, M. (2018). Perception. In F. R. Volkmar (Ed.), Encyclopedia of autism spectrum disorders (pp. 2168-2176). New York, NY: Springer.

Nader, A.-M., Jelenic, P., \& Soulières, I. (2015). Discrepancy between WISC-III and WISC-IV cognitive profile in autism spectrum: What does it reveal about autistic cognition? PLoS One, 10(12), e0144645. https://doi.org/10.1371/journal.pone. 0144645

O'Connor, K. (2012). Auditory processing in autism spectrum disorder: A review. Neuroscience \& Biobehavioral Reviews, 36(2), 836-854. https://doi.org/10.1016/j.neubiorev.2011.11.008

Pell, P. J., Mareschal, I., Calder, A. J., von dem Hagen, E. A. H., Clifford, C. W. G., Baron-Cohen, S., \& Ewbank, M. P. (2016). Intact priors for gaze direction in adults with highfunctioning autism spectrum conditions. Molecular Autism, 7(1), 25. https://doi.org/10.1186/s13229-016-0085-9

Pellicano, E., \& Burr, D. (2012). Response to Brock: Noise and autism. Trends in Cognitive Sciences, 16(12), 574-575. https://doi.org/10.1016/j.tics.2012.10.004

Raven, J., Raven, J. C., \& Court, J. H. (1998). Raven Manual: Section 3. Standard Progressive matrices. Oxford, England: Oxford Psychologists Press.

Redcay, E., \& Courchesne, E. (2008). Deviant functional magnetic resonance imaging patterns of brain activity to speech in 2-3-year-old children with autism spectrum disorder. Biological Psychiatry, 64(7), 589-598. https://doi.org/10.1016/j. biopsych.2008.05.020

Samson, F., Mottron, L., Jemel, B., Belin, P., \& Ciocca, V. (2006). Can spectro-temporal complexity explain the autistic pattern of performance on auditory tasks? Journal of Autism and
Developmental Disorders, 36(1), 65-76. https://doi.org/10. 1007/s10803-005-0043-4

Samson, F., Zeffiro, T. A., Doyon, J., Benali, H., \& Mottron, L. (2015). Speech acquisition predicts regions of enhanced cortical response to auditory stimulation in autism spectrum individuals. Journal of Psychiatric Research, 68, 285-292. https://doi.org/10.1016/j.jpsyc hires.2015.05.011

Sapey-Triomphe, L.-A., Sonié, S., Hénaff, M.-A., Mattout, J., \& Schmitz, C. (2018). Correction to: Adults with autism tend to underestimate the hidden environmental structure: Evidence from a visual associative learning task. Journal of Autism and Developmental Disorders, 48(9), 3075-3075. https://doi.org/ 10.1007/s10803-018-3597-7

Serniclaes, W., Sprenger-Charolles, L., Carré, R., \& Demonet, J. F. (2001). Perceptual discrimination of speech sounds in developmental dyslexia. Journal of Speech, Language, and Hearing Research, 44(2), 384-399.

Serniclaes, W. (2006). Allophonic perception in developmental dyslexia: Origin, reliability and implications of the categorical perception deficit. Written Language \& Literacy, 9(1), 135-152. https://doi.org/10.1075/wll.9.1.09ser

Soulières, I., Dawson, M., Gernsbacher, M. A., \& Mottron, L. (2011). The level and nature of autistic intelligence II: What about Asperger syndrome? PLoS One, 6(9), e25372. https:// doi.org/10.1371/journal.pone.0025372

Soulières, I., Dawson, M., Samson, F., Barbeau, E. B., Sahyoun, C. P., Strangman, G. E., ... Mottron, L. (2009). Enhanced visual processing contributes to matrix reasoning in autism. Human Brain Mapping, 30(12), 4082-4107. https:// doi.org/10.1002/hbm.20831

Stewart, M. E., Petrou, A. M., \& Ota, M. (2018). Categorical speech perception in adults with autism spectrum conditions. Journal of Autism and Developmental Disorders, 48(1), 72-82. https://doi.org/10.1007/s10803-017-3284-0

Teder-Sälejärvi, W. A., Pierce, K. L., Courchesne, E., \& Hillyard, S. A. (2005). Auditory spatial localization and attention deficits in autistic adults. Cognitive Brain Research, 23(2-3), 221-234. https://doi.org/10.1016/j.cogbrainres.2004.10.021

Tryfon, A., Foster, N. E. V., Sharda, M., \& Hyde, K. L. (2018). Speech perception in autism spectrum disorder: An activation likelihood estimation meta-analysis. Behavioral Brain Research, 338, 118-127. https://doi.org/, https://doi.org/10.1016/j.bbr. 2017.10.025

Tubach, J. L., \& Boe, L. J. (1990). Un corpus de transcription phonétique. France: Telecom.

Van de Cruys, S., Evers, K., Van der Hallen, R., Van Eylen, L., Boets, B., de-Wit, L., \& Wagemans, J. (2014). Precise minds in uncertain worlds: Predictive coding in autism. Psychological Review, 121(4), 649-675. https://doi.org/10.1037/ a0037665

Van der Hallen, R., Lemmens, L., Steyaert, J., Noens, I., \& Wagemans, J. (2017). Ensemble perception in autism spectrum disorder: Member-identification versus mean-discrimination: Ensemble perception in ASD. Autism Research, 10(7), 1291-1299. https://doi.org/10.1002/aur.1767

Wagenmakers, J., Love, J., Marsman, M., Jamil, T., Ly, A., Verhagen, J., ... Morey, R. D. (2018). Bayesian inference for psychology. Part II: Example applications with JASP. Psychonomic Bulletin and Review, 25, 58-76. 
Wechsler, D. (2011). WAIS-IV Nouvelle version de l'échelle d'intelligence de Wechsler pour adultes - Quatrième édition. Montreuil, France: ECPA Pearson.

White, S., Frith, U., Milne, E., Rosen, S., Swettenham, J., \& Ramus, F. (2006). A double dissociation between sensorimotor impairments and reading disability: A comparison of autistic and dyslexic children. Cognitive Neuropsychology, 23(5), 748-761. https://doi.org/10.1080/02643290500438607

Williams, D., Payne, H., \& Marshall, C. (2013). Non-word repetition impairment in autism and specific language impairment: Evidence for distinct underlying cognitive causes. Journal of Autism and Developmental Disorders, 43(2), 404-417. https://doi.org/10.1007/s10803-012-1579-8
Wodka, E. L., Mathy, P., \& Kalb, L. (2013). Predictors of phrase and fluent speech in children with autism and severe language delay. Pediatrics, 131(4), e1128-e1134. https://doi.org/ 10.1542/peds.2012-2221

You, R. S., Serniclaes, W., Rider, D., \& Chabane, N. (2017). On the nature of the speech perception deficits in children with autism spectrum disorders. Research in Developmental Disabilities, 61, 158-171. https://doi.org/10.1016/j.ridd.2016.12.009

Zilbovicius, M., Boddaert, N., Belin, P., Poline, J.-B., Remy, P., Mangin, J.-F., ... Samson, Y. (2000). Temporal lobe dysfunction in childhood autism: A PET study. American Journal of Psychiatry, 157(12), 1988-1993. https://doi.org/10.1176/appi.ajp.157. 12.1988 